\title{
The Role of Vascular Calcification in Heart Failure and Cognitive Decline
}

\author{
Hao-Min Cheng ${ }^{a-c} \quad$ Jiun-Jr Wang ${ }^{d} \quad$ Chen-Huan Chen ${ }^{a-c}$ \\ ${ }^{a}$ Center for Evidence-Based Medicine, Department of Medical Education, Taipei Veterans \\ General Hospital, Departments of ${ }^{b}$ Medicine and ${ }^{c}$ Public Health, National Yang-Ming \\ University, Taipei, and d School of Medicine, Fu Jen Catholic University, New Taipei City, \\ Taiwan, ROC
}

\section{Keywords}

Vascular calcification - Arterial stiffness - Hypertension - Cardiovascular disease

\begin{abstract}
Vascular calcification is heterogeneous and triggered by multiple mechanisms. It has been implicated in the development of heart failure with preserved ejection fraction (HFpEF) and cognitive function impairment. Understanding the pathophysiology of vascular calcification may help us improve the management of $\mathrm{HFpEF}$, atherosclerosis, accelerated arterial stiffness, hypertension, and cognitive dysfunction. Currently, there are no effective strategies for treating accelerated arterial stiffness. This may indicate that once arterial stiffness or vascular calcification has developed, it may be less likely to stop the ongoing pathophysiology. Therefore, earlier intervention targeting the probable pathways of vascular calcification may benefit the patients with vascular calcification and related pathological conditions. In this review, we briefly discuss the proposed pathophysiological roles of vascular calcification in the development of heart failure and cognitive decline, the animal models used to study the link between vascular calcification and cardiovascular diseases, and the possible corresponding management strategies.

(c) 2017 S. Karger AG, Basel
\end{abstract}

Vascular calcification is a prevalent finding in the elderly population, associated with the process of vascular aging which is commonly conceptualized as arterial stiffness [1], and usually recognized as a disease marker and prognostic factor for cardiovascular diseases [2-4]. However, given that arterial stiffness has been increasingly implicated in the pathophysiology of heart failure and cognitive decline, vascular calcification, with its inevitable consequence of stiffening arteries, may also play a significant role and serve as a potential intervention target [5].

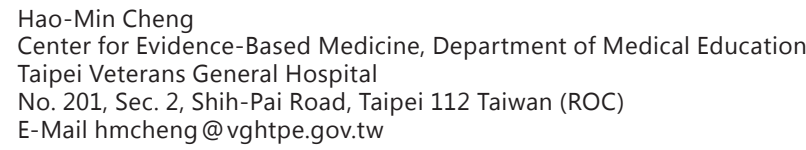




\section{The Role of Vascular Calcification in the Pathophysiology of Cardiovascular Diseases}

Atherosclerosis has been considered as the most important hallmark of vascular pathology. In contrast, arteriosclerosis or arterial stiffness is a vascular aging process [1], which leads to end-organ damage because of the reduced compliance and the arterial reservoir function of the arterial system [6] and the resultant increasing transmitting energy of arterial pulse waves [7]. Vascular calcification, a pathophysiological consequence of atherosclerosis, is associated with an inevitably more stiffened arterial system, and as a result, may serve as a connecting bridge between these two important pathways linked to the development of cardiovascular diseases. Ample evidence shown in animal data and studies of diabetes and end-stage renal disease has demonstrated that calcification of elastic fibers contributes to increased arterial stiffness $[8,9]$.

Henry et al. [10] conducted a large-scale prospective population-based study and found that renal function is inversely associated with cardiovascular and all-cause mortality, in which vascular calcification is the major cause of cardiovascular disease in patients with chronic kidney disease (CKD) as it is associated with myocardial ischemia, impaired myocardial function, valvular insufficiency, arrhythmias and stroke, and appears to be a strong independent predictor of mortality [10]. Besides, patients with atherosclerotic plaque in the intimal layer often have more severely calcified aortae compared to those of the normal population. The prognostic role of calcification of abdominal aorta and coronary arteries in the prediction of incident cardiovascular events has been demonstrated in general population and diabetes patients [11]. Therefore, a deeper comprehension of the pathophysiology of vascular calcification could shed light on the identification of the possible intervention strategies for atherosclerosis and arteriosclerosis.

\section{The Potential Influence of Vascular Calcification on Heart Function and Ventriculo-Arterial Coupling}

It has been reported that more than half of the general population with heart failure have preserved ejection fraction (HFpEF) [12]. Observational studies have concluded that the morbidity of HFpEF is similar to that of systolic heart failure [13]. Interestingly, among elderly women living in the community, HFpEF comprises nearly $90 \%$ of incident heart failure cases [14], in whom vascular calcification and osteoporosis are also common findings. Currently, the treatment of HFpEF is still empirical and there are no evidence-based therapeutic recommendations for this disease [15].

The mechanism underlying HFpEF is complicated. Abnormal matrix dynamics, altered myocyte cytoskeleton, impaired active relaxation, chronotropic incompetence, reduced left atrial strain, and cardiac inflammation on extracellular matrix remodeling are all implicated in the development of HFpEF [16]. Vascular calcification is common in elderly subjects and can lead to increased arterial stiffness. As shown in Figure 1, vascular calcification may play a significant role in the development of HFpEF. Except for the conventional understanding that vascular calcification is closely associated with atherosclerosis and precipitate the ischemic events, vascular calcification may also enhance arterial stiffness and render arterial stiffness less reversible. Subsequently, the reduced aortic reservoir function, which can be conceptualized as the second pump of the circulatory system, can also contribute to the reduced coronary diastolic flow and myocardial ischemia. Moreover, the vascular calcification and related arterial stiffness are associated with increased pulse pressure and consequent elevated left ventricular (LV) afterload. The process that the impaired vascular function 
Cheng et al.: The Role of Vascular Calcification in Heart Failure and Cognitive Decline

Fig. 1. The possible mechanisms through which vascular calcification can cause cardiac damage or dysfunction. LV, left ventricular; HFpEF, heart failure with preserved ejection fraction.

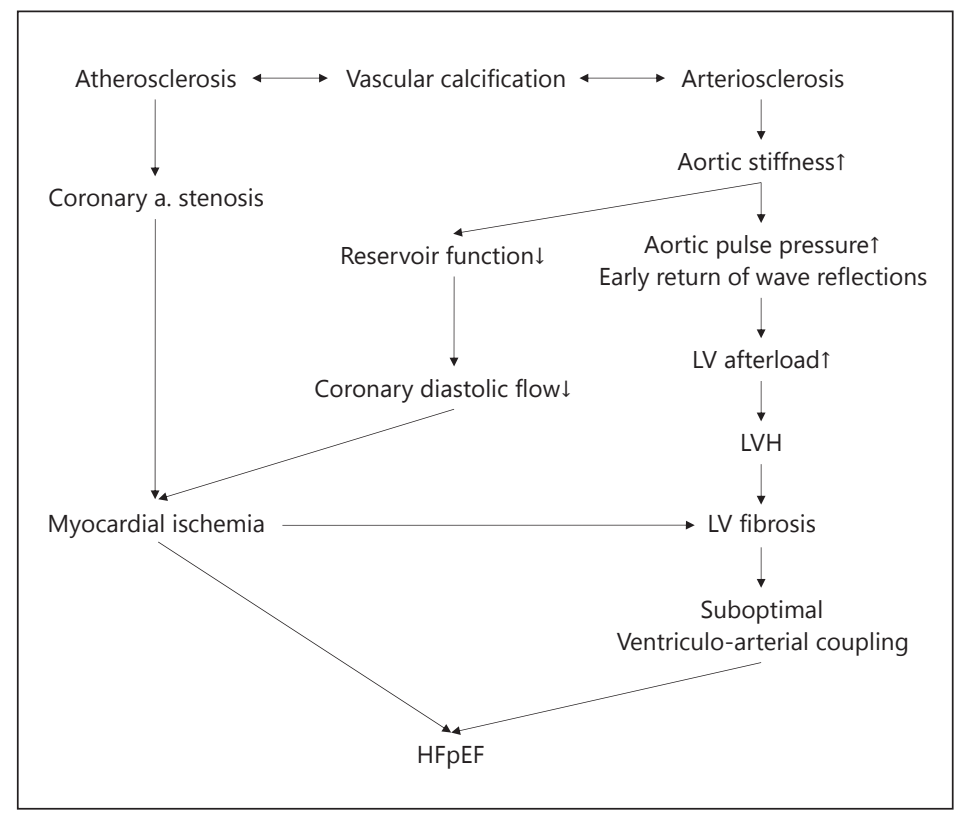

can lead to the worsened LV function is usually coined as ventricular-arterial coupling. As such, targeting ventriculo-arterial coupling, the adverse consequence of vascular calcification, may be helpful to improve the prognosis of HFpEF [17].

\section{Quantification of Ventriculo-Arterial Coupling, an Index Depicting the Interaction between Arteries and Heart}

To quantify the interplay between arteries and heart, an index of ventriculo-arterial coupling has been mathematically modeled [18]. Most LV performance indices, including ejection fraction, stroke volume, and cardiac output, are load-dependent and are influenced by the functional coupling of LV with arteries [19]. The ventriculo-arterial coupling is related to the efficiency of mechanical energetic transfer from the heart to arteries [20]. The physiological significance has been experimentally studied using the framework of the ratio of effective arterial elastance (Ea) to end-systolic elastance (Ees), which is relatively independent of the loading conditions [21]. The normal LV operates efficiently with an Ea/Ees ratio of about 0.6 [22]. The ratio increases as the pump function deteriorates with concomitant peripheral vasoconstriction resulting partly from enhanced sympathetic stimulation and altered baroreceptor gain. The increased Ea/Ees can be significantly reduced by vasodilator therapy which may optimize mechanoenergetic performance of LV in heart failure subjects through lowering peripheral vessel resistance [23]. The utilization of this ventriculoarterial coupling index, Ea/Ees, could assist us in understanding the impact of vascular calcification on cardiac performance [24].

It has been well recognized that cardiovascular morbidity and mortality of patients undergoing dialysis is disproportionally elevated and cannot be fully explained by the high prevalence of established cardiovascular risk factors such as aging, inflammation, hypertension, diabetes mellitus, dyslipidemia, obesity, and smoking [25]. However, these conditions are all closely associated with arterial stiffness and vascular calcification, and are also prevalent in HFpEF. Targeting vascular calcification may help develop effective treatment 
strategies to reduce arterial stiffness and improve the ventriculo-arterial coupling, the mechanical efficiency of cardiac pump.

\section{The Potential Role of Vascular Calcification in the Pathophysiology of Cognitive Dysfunction}

The brain is one of the organs that receive abundant blood supply, constituted by as much as $20 \%$ of cardiac output, and accounts for $20 \%$ of the total body oxygen consumption at rest [26]. High ambient flow and low impedance are thought to sensitize the cerebral microcirculation to harmful effects of excessive pressure and flow pulsatility [27]. Increased carotidfemoral pulse wave velocity (cf-PWV) was modestly associated with cognitive decline and impairment, as assessed using the Modified Mini-Mental State examination [28]. In 167 hypertensive patients without a history of cardiovascular or cerebrovascular disease, a higher cf-PWV was significantly associated with a greater volume of white matter hyperintensities and the presence of lacunar infarcts [29]. Thus, systemic large artery disease is linked to cerebral small-artery disease in hypertensive patients [29]. Furthermore, in the communitybased Age, Gene/Environment Susceptibility - Reykjavik study, cf-PWV was associated with higher white matter hyperintensity volume [27]. Carotid pulsatility index was associated with lower whole brain, grey matter, and white matter volumes [27]. cf-PWV and carotid pulse pressure were associated with lower memory scores [27]. These results support that marked stiffening of the aorta is associated with transmission of excessive flow pulsatility into the brain, microvascular structural brain damage, and lower scores in various cognitive domains [27].

How a stiff aorta facilitates the transmission of high pulsatility of blood flow to the cerebral circulation remains to be clarified. Compared to the carotid arteries, the aorta is highly compliant in young and healthy subjects. Such impedance mismatch constitutes barriers of wave reflections; when a traveling pressure wave from ascending aorta encounters the first-generation arteries, the pulsatile energy would not be fully transmitted into the distal vasculature [27]. Pulse wave encephalopathy has been coined to describe such a hypothetical pathophysiology.

Recently, it has been proposed that arterial stiffness may contribute to the development of symptomatic dementia through a "double hit" mechanism [30]. In this brain MRI and PET imaging study, arterial stiffness was highest in individuals with both high beta-amyloid deposition, a hallmark of Alzheimer disease, and white-matter hyperintensity. Whether or not arterial stiffness is involved in the pathophysiology of Alzheimer disease should be further explored. If there is a true pathophysiological linkage between arterial stiffness and Alzheimer disease, the clarification of the underlying mechanism can provide novel therapeutic targets for these patients. As shown in Figure 2, given that vascular calcification is closely associated with atherosclerosis, cerebral ischemia and cognitive function decline can be anticipated. In addition, vascular calcification and the related increased arterial stiffness can also result in decreased cognitive function through the reduced arterial reservoir function and enhanced transmitting pulsatility of arterial pressure and flow into brain, which altogether cause cerebral damage and cognitive function decline. Therefore, therapeutic strategies to reduce the progression of vascular calcification may be effective to slow down the arterial stiffening and the associated cognitive decline in the aging process.

It is well established that heart failure subjects have worsening cognitive function [3133]. Interestingly, heart failure subjects with hypertension seem to be more likely to develop cognitive dysfunction than those without $[34,35]$. This observation highlights that sustained hypertension related to vascular calcification in this population may compromise cerebral 
Cheng et al.: The Role of Vascular Calcification in Heart Failure and Cognitive Decline

Fig. 2. The possible mechanisms through which vascular calcification can cause cerebral damage or dysfunction.

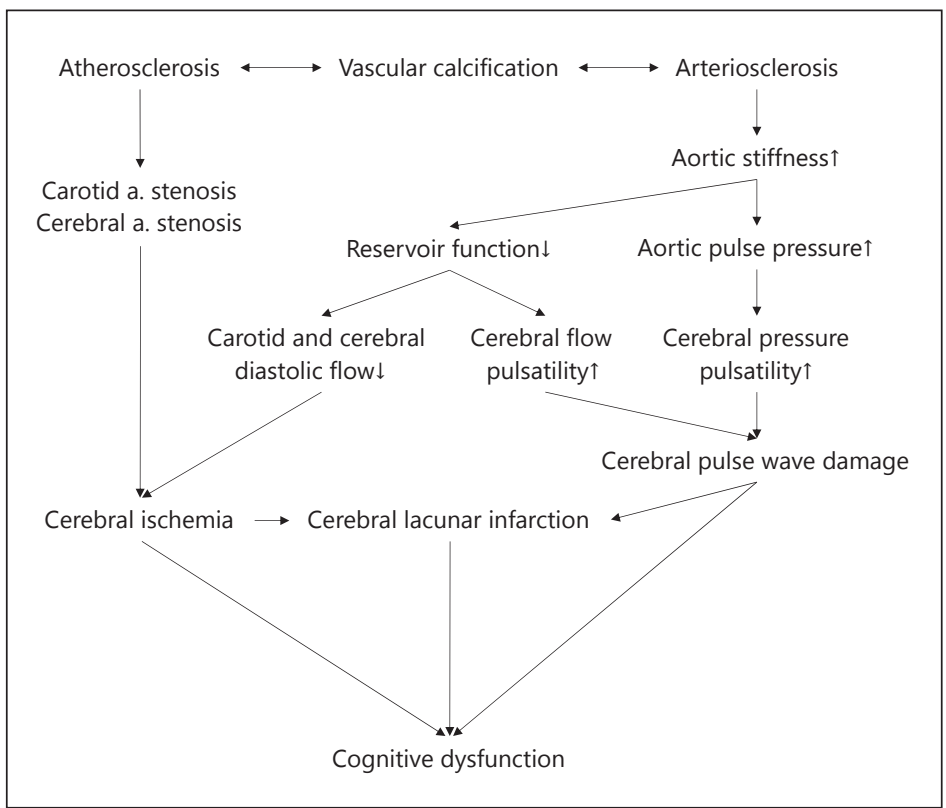

autoregulatory mechanisms and produce brain damage and exacerbate cognitive impairment [30].

Numerous efforts have been made to understand the arterial hemodynamics and its impact on target organ damage and dysfunction. Future research including basic, clinical, and epidemiological studies will be needed to clarify the possible mechanisms depicted as above.

\section{Animal Models of Vascular Calcification}

Animal models allow us to study in detail the progression of a pathological process in a time course of disease development and to have new insights into the cellular mechanism and molecular pathways responsible for these processes. Thus far, there are two categories of animal models for aortic calcification associated with chronic renal failure: (1) calcification in both intimal and medial layer, and (2) calcification mainly in medial layer.

\section{Animal Model of Vascular Calcification in Chronic Renal Failure}

The 5/6th nephrectomy rat model has been used to evaluate uremia-related vascular calcifications. Bro et al. [36] and Buzello et al. [37] induced aortic calcification in both intimal and medial layers in 6 weeks, with no apparent atherosclerosis in tunica media, by inducing a chronic renal failure (5/6th nephrectomy) in apolipoprotein E (apoE) knockout mice. Nasrallah et al. [38] developed a model by inducing CKD, through electrocautery of one kidney followed by nephrectomy of the other, in calcification-prone DBA/2 knockout mice and fed with a $0.9 \%$ high phosphate diet, which led to widespread medial calcification in the vascular tree in 14-15 weeks; they found that the levels of calcification were similar to those observed in humans, without interference of atherosclerosis or inflammation.

Animal Model of Aortic Calcification in the Medial Layer without Chronic Renal Failure

Recently, Price et al. [39] developed a rat model for aortic calcification independent of kidney failure, by treating rats with sufficient warfarin and vitamin $\mathrm{K}$ antagonist that inhibits 


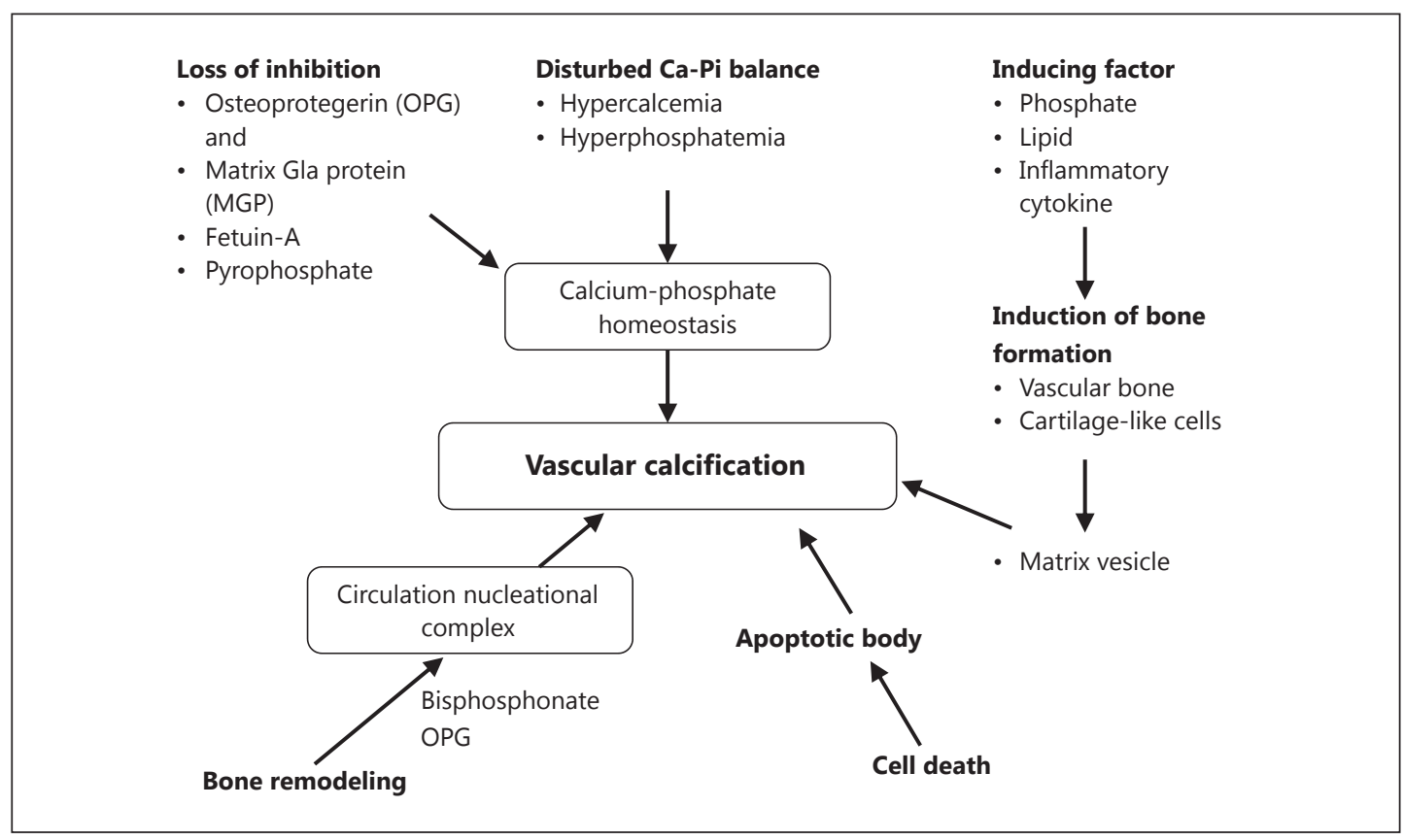

Fig. 3. The potential strategies to target vascular calcification. Adapted from Speer and Giachelli [58].

the formation of the calcium-binding amino acid, g-carboxyglutamic acid (a calcification inhibitor expressed by smooth muscle cells and macrophages in the artery wall in specific proteins), and induced spotty calcification in aortic trees. They also treated rats with vitamin $\mathrm{K}$ to counteract effects of warfarin on coagulation. In a previous cross-sectional human study, the prevalence of arterial calcification was increased in patients with current or past warfarin use independent of other risk factors [9], which suggests prolonged warfarin use is associated with the development of vascular calcification.

\section{Animal Model of Heart Failure and Calcification}

Currently, there is no animal model of vascular calcification directly associated with heart failure. The widely used heart failure rat model is the induced myocardial infarction by coronary artery ligation in Sprague-Dawley male rats. Our experience was that even when the left coronary artery was not completely ligated, heart failure could still develop, resulting from chronic myocardial ischemia. To investigate the interactions between vascular calcification, heart failure, and cognitive function, the combination of the above heart failure and vascular calcification models can be a useful tool for animal studies.

\section{Strategies to Reduce Vascular Calcification and Their Effects on Cardiovascular Functions}

Many novel concepts have been proposed to ameliorate the progression of vascular calcification, which include targets in calcium homeostasis, endothelin receptor, statin, angiotensin receptor blockade, matrix metalloproteinases (MMPs), antidiabetic agents, and chelating agents [5]. Most of these agents remain in primitive stages and their effects on myocardial function are unclear. Figure 3 summarizes the potential strategies to target vascular calcification. 
Many novel concepts have been proposed to target vascular calcification. The possible candidate strategies for reducing or even reverting the progression of vascular calcification are briefly introduced below.

- Phosphate binders: Elevated calcium and phosphate levels contribute to vascular calcification. Decreasing phosphate levels through diet restrictions or through the use of phosphate binders (including calcium-free phosphate binders) is associated with a decreased amount of vascular calcification. It has been shown that sevelamer treatment might contribute to the suppression of ectopic calcification in chronic renal failure [40].

- Vitamin D receptor agonists: In a mouse model of CKD, the administration of vitamin D receptor agonists calcitriol or paricalcitol significantly reduced aortic calcification [41].

- Calcimimetics: Substances that mimic the effects of calcium on the parathyroid gland and decrease the level of parathyroid hormones. Although results from in vitro and animal studies support the hypothesis that calcimimetics decrease vascular calcification [42], the effects are inconsistent [43].

- Bisphosphonates: Based on the assumption that an impaired "bone-vessel axis" is involved in the pathogenesis of vascular calcification, testing the influence of bisphosphonates on vascular calcification is a consequential step. However, the data concerning the impact of bisphosphonates on vascular calcification are inconsistent [44, 45].

- Other substances for osteoporosis therapy: In a mouse osteoporosis model, denosumab reduced aortic calcification [46]. No human studies have been reported yet.

- Calcifying progenitor cells with decalcifying potential [47] has been shown to have the capability to reverse atherosclerotic vascular calcification. The progenitor cells isolated from the aortas of mice had bidirectional, osteoblastic and osteoclastic lineage. The bidirectional cells were demonstrated to increase the severity of calcium build-up and calcified plaques in arteries; however, this effect could be prevented by simultaneous treatment with the PPAR $\gamma$-activating drug, which decreased the infiltration of osteoblasts into the plaques while increasing the infiltration of osteoclasts.

- HMG-CoA reductase inhibitors (statins) and angiotensin II type 1 receptor blockers (ARBs): Statins and ARBs are well-established therapeutic options in cardiovascular medicine and influence atherogenesis effectively. A combination of these substances reduces vascular calcification [48].

- MMPs are activated during vascular calcification and inhibition of MMPs in a CKD rat model has been shown to decrease vascular calcification [49].

- TRAM-34, an inhibitor of intermediate-conductance calcium-activated potassium channels (KCa3.1), inhibited the transition of VSMC into osteoblast-like cells, thus protecting the VSMC from calcification.

- Antidiabetic agent:

- Metformin is a mainstay medication in diabetes therapy and seems to reduce calcification in a rat model via the AMPK-eNOS-NO pathway by increasing NO production [50].

- Advanced glycation end product inhibitors limit vascular calcification in a rat model [51].

- Chelating agents were demonstrated to be effective in reducing vascular calcification in in vitro and animal studies [52]. Dietary L-lysine, vitamin E, and iron effectively reduce vascular calcification in animal models $[53,54]$. 


\section{Conclusion and Future Research}

Vascular calcification is heterogeneous and triggered through multiple mechanisms. Few studies addressed the influence of vascular calcification on ventriculo-arterial coupling status and cognitive function. Understanding the pathophysiology consequence of vascular calcification may help us improve the management of patients with atherosclerosis, accelerated arterial stiffness, hypertension, $\mathrm{HFpEF}$, and cognitive dysfunction. Currently, there have been no effective strategies to reduce the severity of arterial stiffness. This may indicate that once arterial stiffness or vascular calcification has developed, it may be less likely to stop the ongoing pathophysiology. Therefore, earlier intervention targeting the above probable pathways of vascular calcification may benefit the patients with heart failure and cognitive dysfunction. More efforts should be made to understand the mechanisms of this prevalent finding in the aging population and, more importantly, develop corresponding intervention strategies to diminish its adverse consequence. In addition, although the adverse impact of hypertension on cognitive function [55] and the favorable effects of antihypertensive agents on cognitive dysfunction [56] have been well delineated, the evidence supporting the effectiveness of anticalcification therapies on cardiovascular function and cognitive function is scarce [57]. More well-designed outcome research is needed.

\section{Disclosure Statement}

Nothing to declare.

\section{References}

1 McEniery CM, Yasmin, Hall IR, Qasem A, Wilkinson IB, Cockcroft JR; ACCT Investigators: Normal vascular aging: differential effects on wave reflection and aortic pulse wave velocity: The Anglo-Cardiff Collaborative Trial (ACCT). J Am Coll Cardiol 2005;46:1753-1760.

-2 Radford NB, DeFina LF, Barlow CE, Lakoski SG, Leonard D, Paixao AR, Khera A, Levine BD: Progression of CAC score and risk of incident CVD. JACC Cardiovasc Imaging 2016;9:1420-1429.

-3 Abramowitz Y, Jilaihawi H, Chakravarty T, Mack MJ, Makkar RR: Porcelain aorta: a comprehensive review. Circulation 2015;131:827-836.

-4 Shaw LJ, Giambrone AE, Blaha MJ, Knapper JT, Berman DS, Bellam N, Quyyumi A, Budoff MJ, Callister TQ, Min JK: Long-term prognosis after coronary artery calcification testing in asymptomatic patients: a cohort study. Ann Intern Med 2015;163:14-21.

5 Tolle M, Reshetnik A, Schuchardt M, Hohne M, van der Giet M: Arteriosclerosis and vascular calcification: causes, clinical assessment and therapy. Eur J Clin Invest 2015;45:976-985.

6 Belz GG: Elastic properties and Windkessel function of the human aorta. Cardiovasc Drugs Ther 1995;9:73-83.

7 Mitchell GF: Increased aortic stiffness: an unfavorable cardiorenal connection. Hypertension 2004;43:151153.

-8 Mackey RH, Venkitachalam L, Sutton-Tyrrell K: Calcifications, arterial stiffness and atherosclerosis. Adv Cardiol 2007;44:234-244.

-9 Toussaint ND, Kerr PG: Vascular calcification and arterial stiffness in chronic kidney disease: implications and management. Nephrology (Carlton) 2007;12:500-509.

10 Henry RM, Kostense PJ, Bos G, Dekker JM, Nijpels G, Heine RJ, Bouter LM, Stehouwer CD: Mild renal insufficiency is associated with increased cardiovascular mortality: The Hoorn Study. Kidney Int 2002;62:14021407.

11 Bastos Goncalves F, Voute MT, Hoeks SE, Chonchol MB, Boersma EE, Stolker RJ, Verhagen HJ: Calcification of the abdominal aorta as an independent predictor of cardiovascular events: a meta-analysis. Heart 2012;98: 988-994.

-12 Owan TE, Hodge DO, Herges RM, Jacobsen SJ, Roger VL, Redfield MM: Trends in prevalence and outcome of heart failure with preserved ejection fraction. N Engl J Med 2006;355:251-259.

13 Vasan RS, Larson MG, Benjamin EJ, Evans JC, Reiss CK, Levy D: Congestive heart failure in subjects with normal versus reduced left ventricular ejection fraction: prevalence and mortality in a population-based cohort. J Am Coll Cardiol 1999;33:1948-1955. 
14 Gottdiener JS, Arnold AM, Aurigemma GP, Polak JF, Tracy RP, Kitzman DW, Gardin JM, Rutledge JE, Boineau RC: Predictors of congestive heart failure in the elderly: The Cardiovascular Health Study. J Am Coll Cardiol 2000;35:1628-1637.

-15 Massie BM, Carson PE, McMurray JJ, Komajda M, McKelvie R, Zile MR, Anderson S, Donovan M, Iverson E, Staiger C, Ptaszynska A: Irbesartan in patients with heart failure and preserved ejection fraction. N Engl J Med 2008;359:2456-2467.

16 Udelson JE: Heart failure with preserved ejection fraction. Circulation 2011;124:e540-e543.

17 Paneni F, Diaz Canestro C, Libby P, Luscher TF, Camici GG: The aging cardiovascular system: understanding it at the cellular and clinical levels. J Am Coll Cardiol 2017;69:1952-1967.

18 Cheng HM, Yu WC, Sung SH, Wang KL, Chuang SY, Chen CH: Usefulness of systolic time intervals in the identification of abnormal ventriculo-arterial coupling in stable heart failure patients. Eur J Heart Fail 2008;10: 1192-1200.

19 Sunagawa K, Maughan WL, Sagawa K: Stroke volume effect of changing arterial input impedance over selected frequency ranges. Am J Physiol 1985;248:H477-H484.

20 Burkhoff D, Sagawa K: Ventricular efficiency predicted by an analytical model. Am J Physiol 1986;250:R1021R1027.

21 Sunagawa K, Maughan WL, Sagawa K: Optimal arterial resistance for the maximal stroke work studied in isolated canine ventricle. Circ Res 1985;56:586-595.

-22 Asanoi H, Sasayama S, Kameyama T: Ventriculoarterial coupling in normal and failing heart in humans. Circ Res 1989;65:483-493.

-23 Zile MR, Baicu CF, Gaasch WH: Diastolic heart failure - abnormalities in active relaxation and passive stiffness of the left ventricle. N Engl J Med 2004;350:1953-1959.

24 Chantler PD, Lakatta EG: Arterial-ventricular coupling with aging and disease. Front Physiol 2012;3:90.

25 Schiffrin EL, Lipman ML, Mann JF: Chronic kidney disease: effects on the cardiovascular system. Circulation 2007;116:85-97.

26 Markus HS: Cerebral perfusion and stroke. J Neurol Neurosurg Psychiatry 2004;75:353-361.

-27 Mitchell GF, van Buchem MA, Sigurdsson S, Gotal JD, Jonsdottir MK, Kjartansson O, Garcia M, Aspelund T, Harris TB, Gudnason V, Launer LJ: Arterial stiffness, pressure and flow pulsatility and brain structure and function: The Age, Gene/Environment Susceptibility - Reykjavik Study. Brain 2011;134:3398-3407.

28 Zeki Al Hazzouri A, Newman AB, Simonsick E, Sink KM, Sutton Tyrrell K, Watson N, Satterfield S, Harris T, Yaffe K: Pulse wave velocity and cognitive decline in elders: the health, aging, and body composition study. Stroke 2013;44:388-393.

-29 Henskens LH, Kroon AA, van Oostenbrugge RJ, Gronenschild EH, Fuss-Lejeune MM, Hofman PA, Lodder J, de Leeuw PW: Increased aortic pulse wave velocity is associated with silent cerebral small-vessel disease in hypertensive patients. Hypertension 2008;52:1120-1126.

-30 Hughes TM, Kuller LH, Barinas-Mitchell EJ, Mackey RH, McDade EM, Klunk WE, Aizenstein HJ, Cohen AD, Snitz BE, Mathis CA, Dekosky ST, Lopez OL: Pulse wave velocity is associated with beta-amyloid deposition in the brains of very elderly adults. Neurology 2013;81:1711-1718.

-31 Vogels RL, Scheltens P, Schroeder-Tanka JM, Weinstein HC: Cognitive impairment in heart failure: a systematic review of the literature. Eur J Heart Fail 2007;9:440-449.

-32 Jefferson AL, Beiser AS, Himali JJ, Seshadri S, O’Donnell CJ, Manning WJ, Wolf PA, Au R, Benjamin EJ: Low cardiac index is associated with incident dementia and Alzheimer disease: The Framingham Heart Study. Circulation 2015;131:1333-1339.

-33 Jefferson AL, Himali JJ, Beiser AS, Au R, Massaro JM, Seshadri S, Gona P, Salton CJ, DeCarli C, O’Donnell CJ, Benjamin EJ, Wolf PA, Manning WJ: Cardiac index is associated with brain aging: The Framingham Heart Study. Circulation 2010;122:690-697.

-34 Alosco ML, Brickman AM, Spitznagel MB, van Dulmen M, Raz N, Cohen R, Sweet LH, Colbert LH, Josephson R, Hughes J, Rosneck J, Gunstad J: The independent association of hypertension with cognitive function among older adults with heart failure. J Neurol Sci 2012;323:216-220.

-35 Komori T, Eguchi K, Saito T, Nishimura Y, Hoshide S, Kario K: Riser blood pressure pattern is associated with mild cognitive impairment in heart failure patients. Am J Hypertens 2016;29:194-201.

-36 Bro S, Bentzon JF, Falk E, Andersen CB, Olgaard K, Nielsen LB: Chronic renal failure accelerates atherogenesis in apolipoprotein E-deficient mice. J Am Soc Nephrol 2003;14:2466-2474.

-37 Buzello M, Tornig J, Faulhaber J, Ehmke H, Ritz E, Amann K: The apolipoprotein E knockout mouse: a model documenting accelerated atherogenesis in uremia. J Am Soc Nephrol 2003;14:311-316.

-38 Nasrallah MM, El-Shehaby AR, Salem MM, Osman NA, El Sheikh E, Sharaf El Din UA: Fibroblast growth factor-23 (FGF-23) is independently correlated to aortic calcification in haemodialysis patients. Nephrol Dial Transplant 2010;25:2679-2685.

-39 Price PA, Faus SA, Williamson MK: Warfarin-induced artery calcification is accelerated by growth and vitamin D. Arterioscler Thromb Vasc Biol 2000;20:317-327.

40 Katsumata K, Kusano K, Hirata M, Tsunemi K, Nagano N, Burke SK, Fukushima N: Sevelamer hydrochloride prevents ectopic calcification and renal osteodystrophy in chronic renal failure rats. Kidney Int 2003;64:441450 . 
-41 Lau WL, Leaf EM, Hu MC, Takeno MM, Kuro-o M, Moe OW, Giachelli CM: Vitamin D receptor agonists increase klotho and osteopontin while decreasing aortic calcification in mice with chronic kidney disease fed a high phosphate diet. Kidney Int 2012;82:1261-1270.

42 Torres PA, De Broe M: Calcium-sensing receptor, calcimimetics, and cardiovascular calcifications in chronic kidney disease. Kidney Int 2012;82:19-25.

-43 Carney EF: Chronic kidney disease: no significant effect of cinacalcet on cardiovascular outcomes in patients undergoing dialysis - EVOLVE results. Nat rev Nephrol 2013;9:4.

-44 Lomashvili KA, Monier-Faugere MC, Wang X, Malluche HH, O’Neill WC: Effect of bisphosphonates on vascular calcification and bone metabolism in experimental renal failure. Kidney Int 2009;75:617-625.

45 Toussaint ND, Lau KK, Strauss BJ, Polkinghorne KR, Kerr PG: Effect of alendronate on vascular calcification in CKD stages 3 and 4: a pilot randomized controlled trial. Am J Kidney Dis 2010;56:57-68.

-46 Helas S, Goettsch C, Schoppet M, Zeitz U, Hempel U, Morawietz H, Kostenuik PJ, Erben RG, Hofbauer LC: Inhibition of receptor activator of NF-kappaB ligand by denosumab attenuates vascular calcium deposition in mice. Am J Pathol 2009;175:473-478.

47 Cho HJ, Cho HJ, Lee HJ, Song MK, Seo JY, Bae YH, Kim JY, Lee HY, Lee W, Koo BK, Oh BH, Park YB, Kim HS: Vascular calcifying progenitor cells possess bidirectional differentiation potentials. PLoS Biol 2013; 11:e1001534.

-48 Iijima K, Ito Y, Son BK, Akishita M, Ouchi Y: Pravastatin and olmesartan synergistically ameliorate renal failureinduced vascular calcification. J Atheroscler Thromb 2014;21:917-929.

-49 Chen NX, O’Neill KD, Chen X, Kiattisunthorn K, Gattone VH, Moe SM: Activation of arterial matrix metalloproteinases leads to vascular calcification in chronic kidney disease. Am J Nephrol 2011;34:211-219.

-50 Cao X, Li H, Tao H, Wu N, Yu L, Zhang D, Lu X, Zhu J, Lu Z, Zhu Q: Metformin inhibits vascular calcification in female rat aortic smooth muscle cells via the AMPK-eNOS-NO pathway. Endocrinology 2013;154:3680-3689.

51 Brodeur MR, Bouvet C, Bouchard S, Moreau S, Leblond J, Deblois D, Moreau P: Reduction of advanced-glycation end products levels and inhibition of rage signaling decreases rat vascular calcification induced by diabetes. PLoS One 2014;9:e85922.

52 Lei Y, Grover A, Sinha A, Vyavahare N: Efficacy of reversal of aortic calcification by chelating agents. Calcif Tissue Int 2013;93:426-435.

53 Shimomura A, Matsui I, Hamano T, Ishimoto T, Katou Y, Takehana K, Inoue K, Kusunoki Y, Mori D, Nakano C, Obi Y, Fujii N, Takabatake Y, Nakano T, Tsubakihara Y, Isaka Y, Rakugi H: Dietary L-lysine prevents arterial calcification in adenine-induced uremic rats. J Am Soc Nephrol 2014;25:1954-1965.

54 Peralta-Ramirez A, Montes de Oca A, Raya AI, Pineda C, Lopez I, Guerrero F, Diez E, Munoz-Castaneda JR, Martinez J, Almaden Y, Rodriguez M, Aguilera-Tejero E: Vitamin e protection of obesity-enhanced vascular calcification in uremic rats. Am J Physiol Renal Physiol 2014;306:F422-F429.

55 Tadic M, Cuspidi C, Hering D: Hypertension and cognitive dysfunction in elderly: blood pressure management for this global burden. BMC Cardiovasc Disord 2016;16:208.

56 Levi Marpillat N, Macquin-Mavier I, Tropeano AI, Bachoud-Levi AC, Maison P: Antihypertensive classes, cognitive decline and incidence of dementia: a network meta-analysis. J Hypertens 2013;31:1073-1082.

57 Vo TM, Disthabanchong S: Are there ways to attenuate arterial calcification and improve cardiovascular outcomes in chronic kidney disease? World J Cardiol 2014;6:216-226.

-58 Speer MY, Giachelli CM: Regulation of cardiovascular calcification. Cardiovasc Pathol 2004;13:63-70. 